\title{
Study on Air Film Formation Mechanism and Cooling in Large-Span Air-Conditioning Plant Rooms without Natural Wind
}

\author{
Xiaoyong Peng, Yuan Zhang, Weili Gu, Han Xiong, Yu Li \\ School of Civil Engineering, University of South China, Hengyang, China \\ Email: Pengxiaoyong@126.com
}

How to cite this paper: Peng, X.Y., Zhang, Y., Gu, W.L., Xiong, H. and Li, Y. (2018) Study on Air Film Formation Mechanism and Cooling in Large-Span Air-Conditioning Plant Rooms without Natural Wind. Journal of Applied Mathematics and Physics, 6, 1596-1605.

https://doi.org/10.4236/jamp.2018.68135

Received: June 8, 2018

Accepted: August 6, 2018

Published: August 9, 2018

\begin{abstract}
Large-span air-conditioning plant rooms have a large roof area and suffer from serious solar radiation in summer. The outside roof surface temperature is very high, so cooling load of roof occupies a large proportion in the envelope structure cooling load of large-span air-conditioning plant rooms. Based on the Coanda airfoil air induction unit, the author combined with exhaust air in large-span air-conditioning plant rooms to design the roof air film cooling system of large-span air-conditioning plant rooms. The adherence air film formed on the outside surface takes away heat on the outside surface of the roof, so as to reduce outside roof surface temperature of the roof, decrease heat transfer temperature difference between inside and outside roof surfaces of, and reduce roof cooling cold. Furthermore, the mathematical model and numerical simulation method of considering fluid-structure interaction for heat transfer and influences of solar radiation on air film formation of outside surface and cooling were constructed. Moreover, the numerical simulation method was conducted the validation of effectiveness. Also, the author discussed the air film formation mechanism and air film cooling ability of outside surface in large-span air-conditioning plant rooms without natural wind, developed a new air film cooling technology for the roof of large-span air-conditioning plant rooms, and supplemented the existing roof cooling technology.
\end{abstract}

\section{Keywords}

Air Film, Numerical Simulation, Coanda Effect, Cooling

\section{Introduction}

The roof of large-span air-conditioning plant rooms is often exposed to the 
strong solar radiation in summer. In addition, the outside surface of the surface has the high temperature and the roof area has the large proportion in the envelope structure of large-span air-conditioning plant rooms, so the cooling load of the roof has a large proportion in envelope structure cooling load of large-span air-conditioning plant rooms.

Domestic and overseas studies about roof energy-saving technology mainly include cooling roof technology [1] [2], green roof technology [3] [4] and roof sprinkler technology [5] [6], which can reduce the outside surface temperature of the roof and decrease the heat transfer temperature difference between inside and outside surfaces of the roof, so as to effectively reduce cooling load and reach the excellent energy-saving effect.

The air film cooling technology started being used to cool high-temperature components in aircraft engines in the 1970s. Hunley [7] used CFD numerical simulation method to verify the method of improving air film cooling efficiency. Li Jia [8] constructed the experimental measuring system for panel air film cooling and cascade air film cooling and applied pressure sensitive lacquer to measure the air film cooling efficiency. Ding Yang [9] et al utilized the numerical simulation method to conduct the comparative study on the flow field characteristics of full-coverage air film cooling structure, surface coefficient of heat transfer for the wall, and air film cooling efficiency. Zhang Yang [10] adopted the pressure sensitive lacquer experiment technology to do an experimental study on the plane cascade end wall's air film cooling characteristic of high-pressure turbine rotors

Based on the Coanda airfoil air induction unit, the author combined with exhaust air in large-span air-conditioning plant rooms to design the roof air film cooling system of large-span air-conditioning plant rooms, constructed mathematical model and numerical simulation method of fluid-structure interaction between air film of outside surface and garret, as well as influences of solar radiation on outside surface air film on the roof, conducted the validation of effectiveness for numerical simulation method and discussed influences of Coanda airfoil air induction unit's supply velocity on the outside surface air film formulation mechanism, cooling effect and inside roof temperature distribution.

\section{Numerical Simulation Method and Validation of Effectiveness}

\subsection{Control Equation}

\subsubsection{Flow Control Equation}

The upper air movement above the roof of the large-span air-conditioning plant rooms studied in this paper referred to the low-speed incompressible turbulence flow. Due to high outside surface temperature in the large-span air-conditioning plant rooms, the hot buoyancy should be considered. As a result, Boussinesq assumption was used. In other words, viscous dissipation in flow was neglected. Except for the air density, other physical parameters were constants. The mo- 
mentum equation showed that only air density in buoyancy was changed, while density of other items was unchanged. The control equation was shown in Formula (1), Formula (2) and Formula (3).

1) Mass conservation equation

$$
\frac{\partial u_{j}}{\partial x_{j}}=0
$$

2) Momentum conservation equation

$$
\frac{\partial\left(\rho u_{i}\right)}{\partial t}+\frac{\partial\left(\rho u_{i} u_{j}\right)}{\partial x_{j}}=-\frac{\partial p}{\partial x_{i}}+\frac{\partial}{\partial x_{j}}\left[\eta_{e f f}\left(\frac{\partial u_{i}}{\partial x_{i}}+\frac{\partial u_{i}}{\partial x_{i}}\right)\right]+\rho \beta\left(T_{0}-T\right) g_{i}
$$

3) Energy conservation equation

$$
\frac{\partial(\rho T)}{\partial T}+\operatorname{div}(\rho \overrightarrow{\mathrm{u}} T)=\operatorname{div}\left(\frac{h}{C_{p}} \operatorname{grad} T\right)+S_{T}
$$

In the above-mentioned equations, $u_{j}$ is the velocity, $f_{i}$ is the body force, $\rho$ is density, $P$ is pressure, $\mu$ is dynamic viscosity coefficient, $V$ is kinematic coefficient of viscosity, $u_{i}$ is the average velocity, $u_{i}$ ' is the pulsation of velocity, $T$ is temperature, $h$ is the heat transfer coefficient, $c_{p}$ is the specific heat and $S_{T}$ is the source item.

\subsubsection{The Roof Heat Conduction Equation and Heat Transfer Boundary of Fluid-Structure Interaction}

The fluid-structure interaction heat transfer problem is formed between the air film area of outside roof surface in the large-span air-conditioning plant rooms and internal solid area of the garret. The boundary condition is dynamically determined by the heat exchange process, so it can't be given in advance. In the numerical solution process, different equations were used to solve the fluid domain and solid domain and used continuity, thermal flux and temperature of equations as the exchange data of fluid-solid boundary.

The roof heat transfer process of large-scan air-conditioning plant rooms is the steady-state heat transfer. The material is the color steel sheet roofing, showing the high thermal diffusivity. When the outside roof surface is conducted air film cooling, internal temperature change of roof is fast, so it has no need to consider thermal storage of garret. The heat transfer equation of the roof gets involved in constant property, no internal heat source and steady-state heat conduction equation. The specific form under the rectangular coordinate system is shown in Formula (4):

$$
\frac{\partial^{2} T}{\partial x^{2}}+\frac{\partial^{2} T}{\partial y^{2}}+\frac{\partial^{2} T}{\partial z^{2}}=0
$$

\subsection{Numerical Simulation Method and Validation of Effectiveness}

In this paper, the author extracted the calculation model from the panel convective heat transfer experiment of R.S. AbduNour [11] et al. The specific experimental process could transfer to the reference [11]. The numerical simulation 


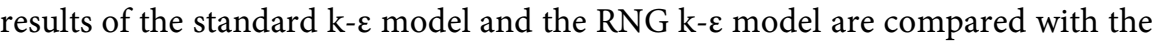
experimental results of R.S. AbdulNour et al.

The geometric model simulation calculated by numerical modeling is present in Figure 1. The outside panel wall surface is the heat flux wall surface, heat flux $1050 \mathrm{w} / \mathrm{m}^{2}$, air distributor width $\mathrm{w}=20 \mathrm{~cm}$. The speed inlet boundary condition is applied. The jet flow entrance speed is $6 \mathrm{~m} / \mathrm{s}$ and temperature is $22^{\circ} \mathrm{C}$. The panel wall thickness could be used to calculate the outside boundary.

The section speed distribution comparison is illustrated in Figure 2. The simulated results of the standard k- $\varepsilon$ model and RNG k- $\varepsilon$ model could be relatively identical to the experimental results. However, the near wall region has had the small difference from the experimental results. Therefore, this paper used the

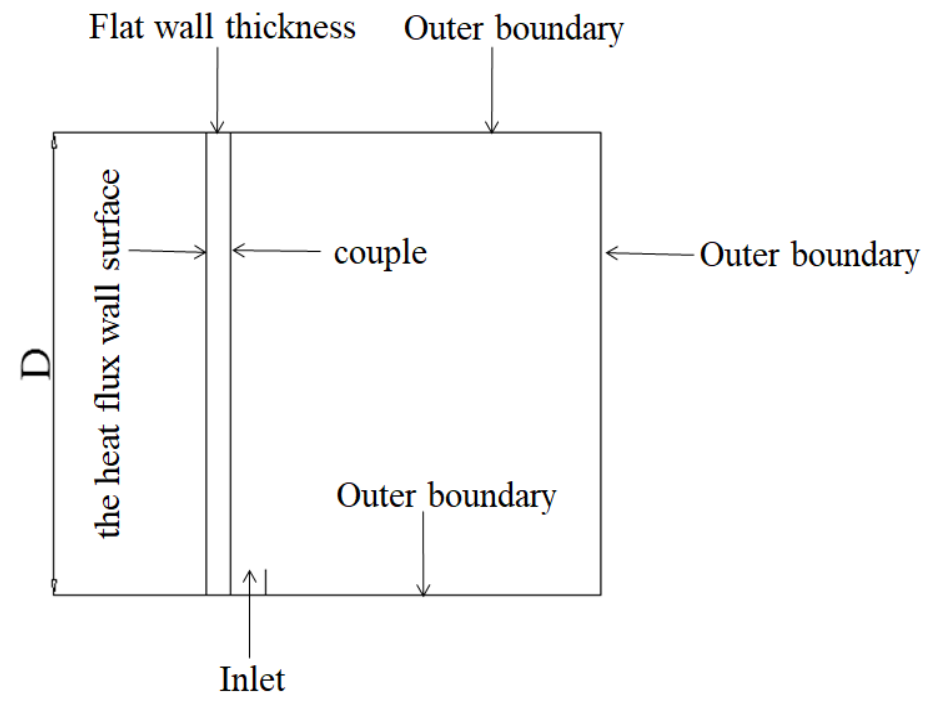

Figure 1. The geometric model.

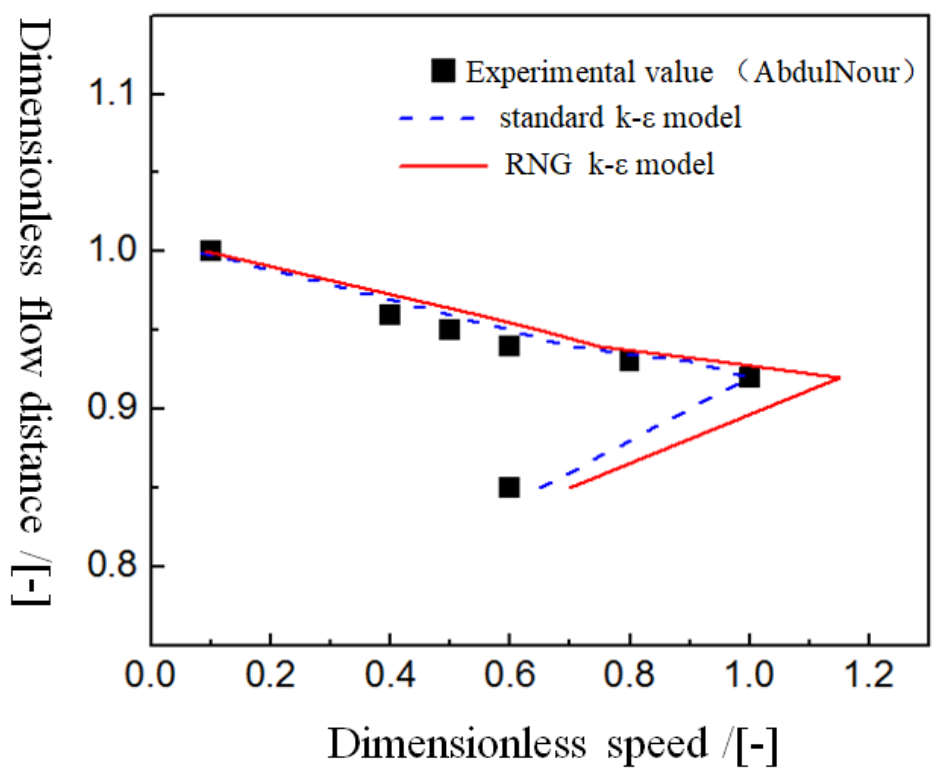

Figure 2. The section speed distribution comparison. 
standard $\mathrm{k}-\varepsilon$ model to do mesh encryption in the near wall region. Meanwhile, the wall-function method was used to deal with the near wall region. The numerical modeling result could be reliable, including dimensionless speed and dimensionless flow distance.

\subsection{Physical Model}

The roof air film cooling physical model of large-span air-conditioning plant rooms and computational domain are shown in Figure 3. Assuming that the outside roof surface air movement is the two-dimensional non-spanwise flow, the solar radiation model in Fluent software only can be suitable for the $3 \mathrm{D}$ physical model. In order to load the solar radiation model, the length was $1 \mathrm{~m}$. The $3 \mathrm{D}$ physical model that was symmetric in front and back along $\mathrm{Z}$ axis was selected as the research object. The roof is the low-temperature profiled sheet roof with the thickness of $0.1 \mathrm{~m}$. Air induction unit is present in the detail drawing of the air induction unit, which is mainly composed of the air distributor and Coanda curve. The air distributor is the strip tuyere. The slit type air distributor is vertical to the Coanda curve. Moreover, the air induction unit is composed of the air distributor and Coanda curve. The air distributor is the strip tuyere. The split tyreye arrives in Coanda curve. The split type baggage is vertical to the Coanda curve. Besides, the length of split air distributor along $\mathrm{Z}$ direction is $1 \mathrm{~m}$. The height along the $\mathrm{Y}$ direction is $0.02 \mathrm{~m}$.

\subsection{Mesh Generation and Boundary Condition}

In this paper, hexahedral mesh was used to divide the computational domain. Moreover, the local cipher should be conducted in the air distributor of cooling induction unit and outside roof surface.

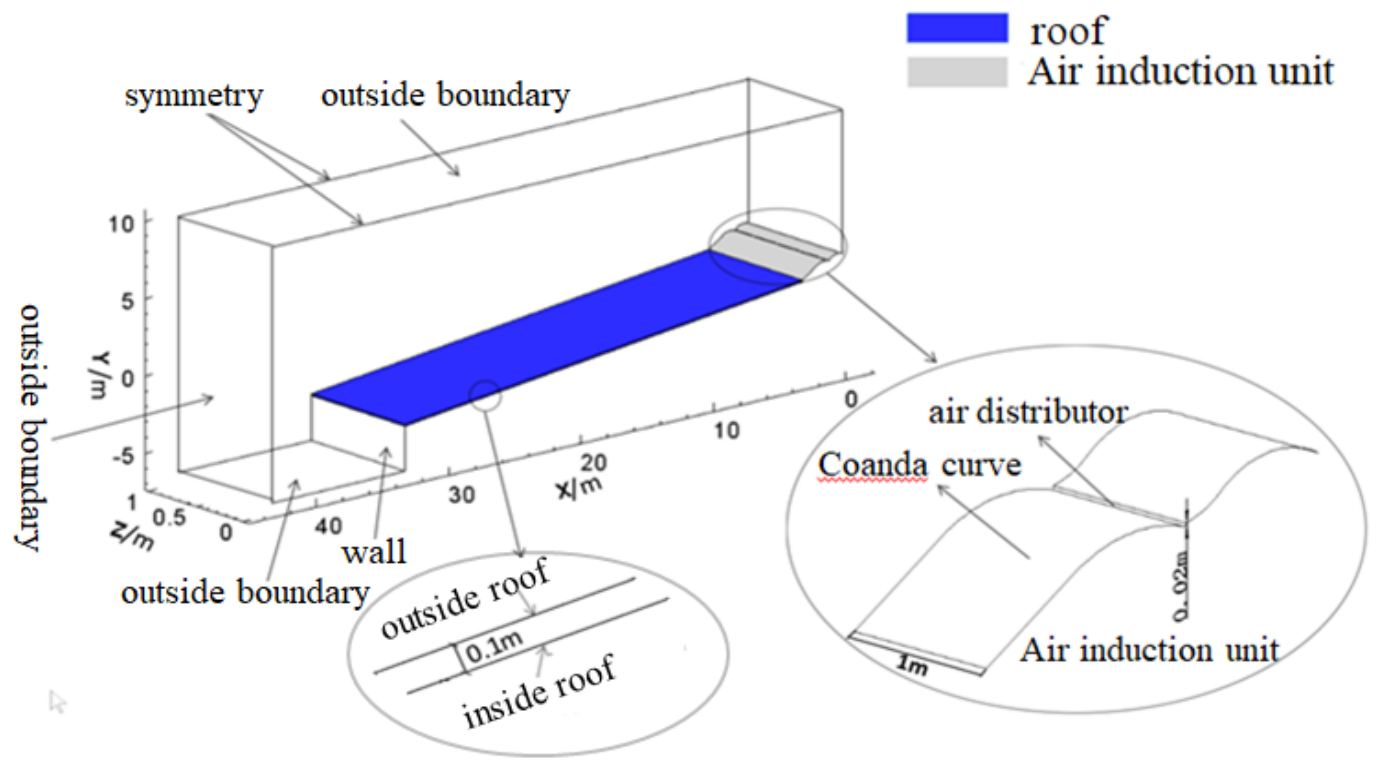

Figure 3. Physical model and computation area. 
The air distributor of air induction outlet is the speed entrance. The supply air temperature is $\mathrm{T}=305 \mathrm{k}$. The even air supply velocity of the cabin is $\mathrm{u}_{0}$. The air supply velocity is vertical to the split type air distributor. The outside roof surface can be the coupling surface, while constant temperature of inside roof temperature is $\mathrm{T}=303 \mathrm{~K}$. The calculation of extraterritorial outside boundary is the export boundary. Both sides can be called as the symmetric boundary condition. The absorbance of roof for solar radiation is 0.8 , while heat transfer coefficient is $3.87 \mathrm{~W} / \mathrm{m}^{2} \cdot \mathrm{k}$

\section{The Numerical Simulation Result and Analysis}

\subsection{The Simulated Results and Analysis of Different Air Supply Velocity on the Formulation of Roof Air Film}

\subsubsection{Flow Analysis}

The motion pattern of air induction unit is illustrated in Figure 4, while the overall flow of the computational domain is Figure 5. As shown in Figure 4 and Figure 5, the streamline around Coanda air induction unit is arc-shaped. The supply air velocity of narrow slit outlet is high, while airflow in supply air velocity of narrow slit outlet can flow rightward. At the same time, negative pressure area is formed around the Coanda curve, so that ambient air can form the supplement for the negative pressure area, so as to realize small air volume induction.

\subsubsection{The Formative Analysis of Air Film}

The normal section velocity profile along the roof method is present Figure 6 . There is the probably the same regular in any section position and velocity distribution. In other words, the velocity of positive direction along the vertical coordinates $y$ is firstly increasing and then decreasing and finally it tends to be

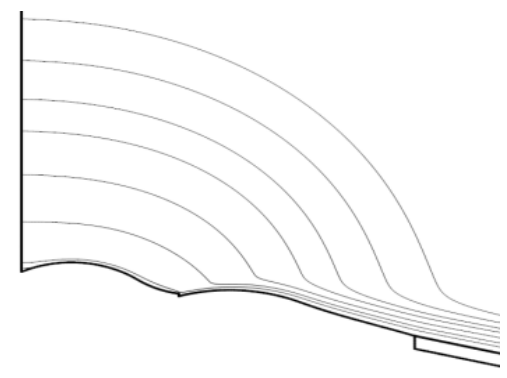

Figure 4. Motion pattern.

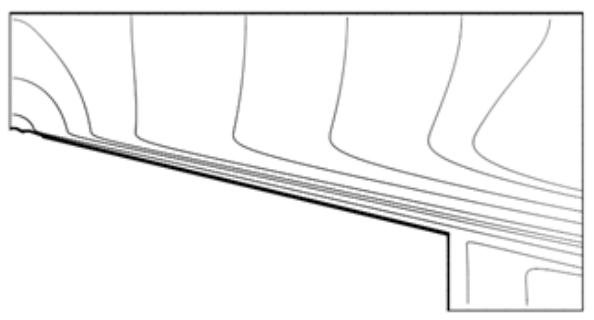

Figure 5. The overall streamline. 


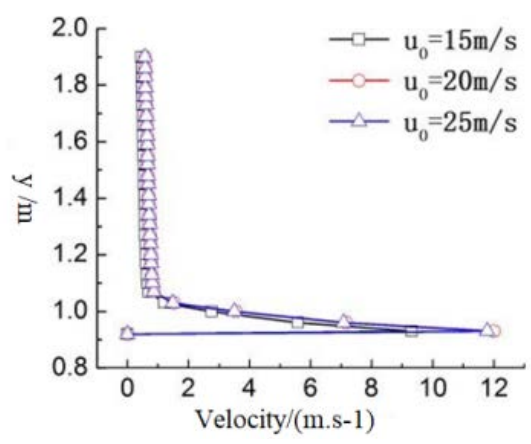

(a)

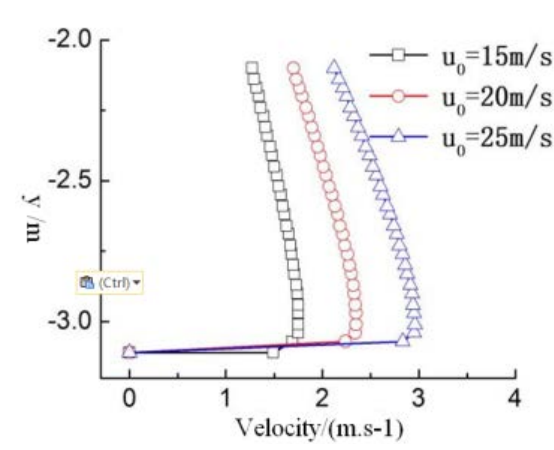

(d)

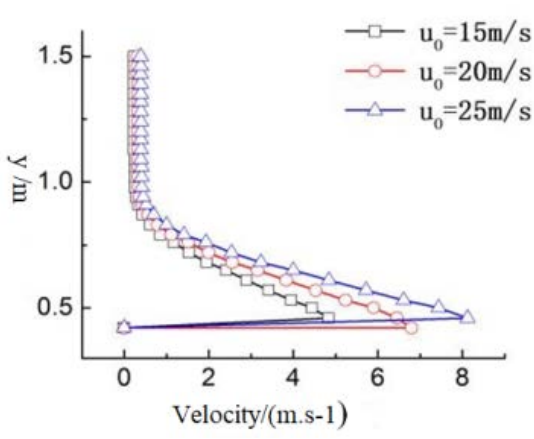

(b)

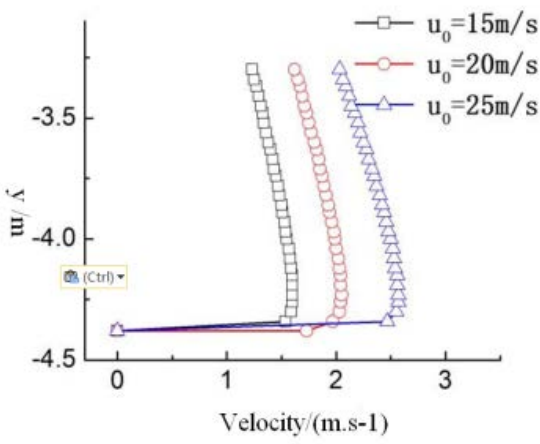

(e)

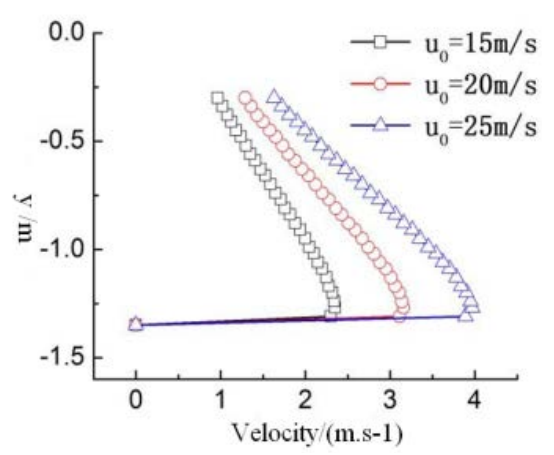

(c)

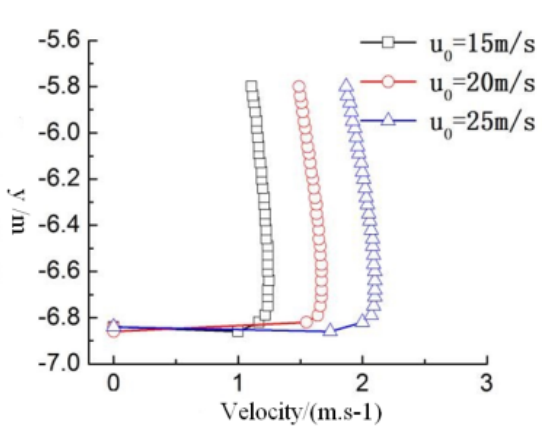

(f)

Figure 6. The section velocity distribution along the roof normal coordinates. (a) $\mathrm{X}=1 \mathrm{~m}$; (b) $\mathrm{X}=3 \mathrm{~m}$; (c) $\mathrm{X}=10 \mathrm{~m}$; (d) $\mathrm{X}=17$ $\mathrm{m}$; (e) $\mathrm{X}=22 \mathrm{~m}$; (f) $\mathrm{X}=32 \mathrm{~m}$.

stable. With the increase of movement distance and gradual increase of air film areas, the adherence velocity of air film is gradually reduced. In $\mathrm{X}=1 \mathrm{~m}$, air film has the minimal area, while air film has the maximum adherence velocity. At $\mathrm{X}$ $=32 \mathrm{~m}$, the air film area is the biggest one, while air film has adherence speed. The aril film area is minimal. Air film area is more obvious with the increase of air supply speed.

\subsection{The Simulated Results and Analysis of Influences of Different Supply Air Velocity on Roof Cooling}

The air temperature profile at $1 \mathrm{~cm}$ above roof of the large-span air-conditioning plant rooms is shown in Figure 7, showing that air temperature is increased with the increase of air flow distance. There is the biggest temperature rising in the least significant end of roof. Moreover, with the increase of supply air velocity, air temperature rising is reduced.

The air temperature cloud figure above the outside roof surface of large-span air-conditioning plant rooms is illustrated in Figure 8, revealing that the air temperature stratification of outside roof surface has the temperature stratification. As closing to the outside roof surface, the air temperature will be higher. With the increase of air movement distance, air film can constantly bring away the heat on the outside roof surface. Moreover, the air temperature is gradually increased. 
The surface temperature comparison of large-span air-conditioning plant rooms under the different air supply velocity is shown in Figure 9. It can be observed that with the increase of air movement distance, outside roof surface temperature is increasing. With the increase of air supply velocity, the outside roof surface is lower, the cooling temperature difference is larger and cooling effect will be better.

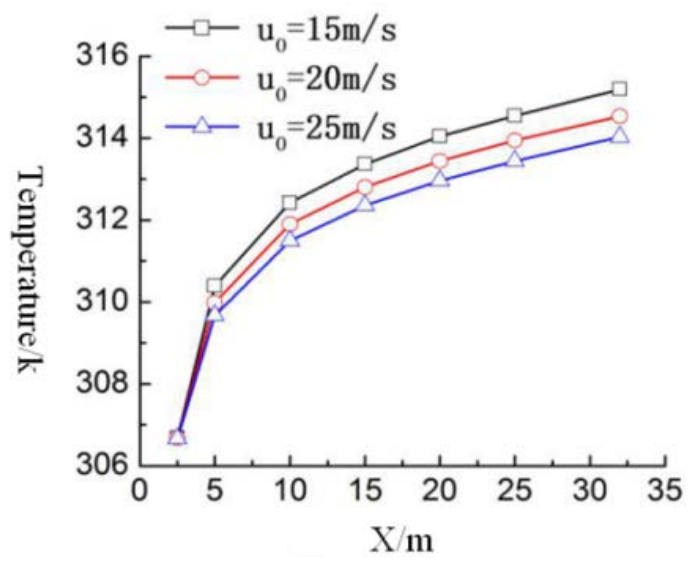

Figure 7. The air temperature profile.

Temperature/k

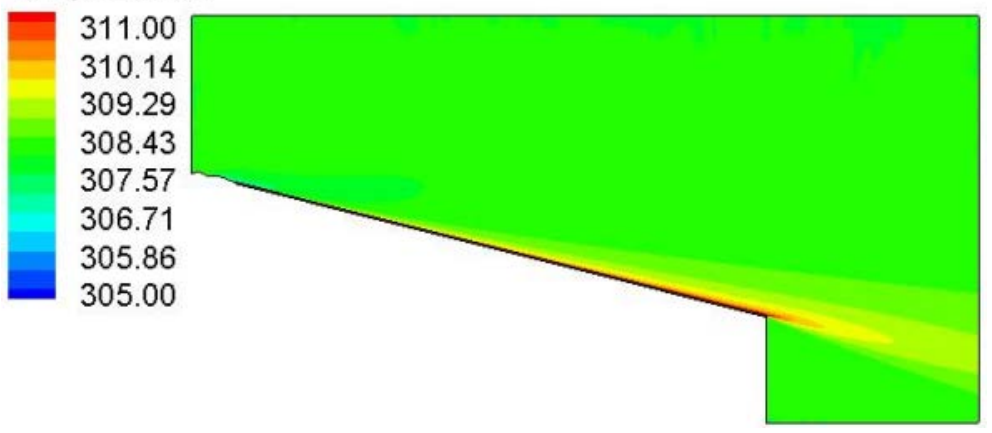

Figure 8. Air temperature cloud.

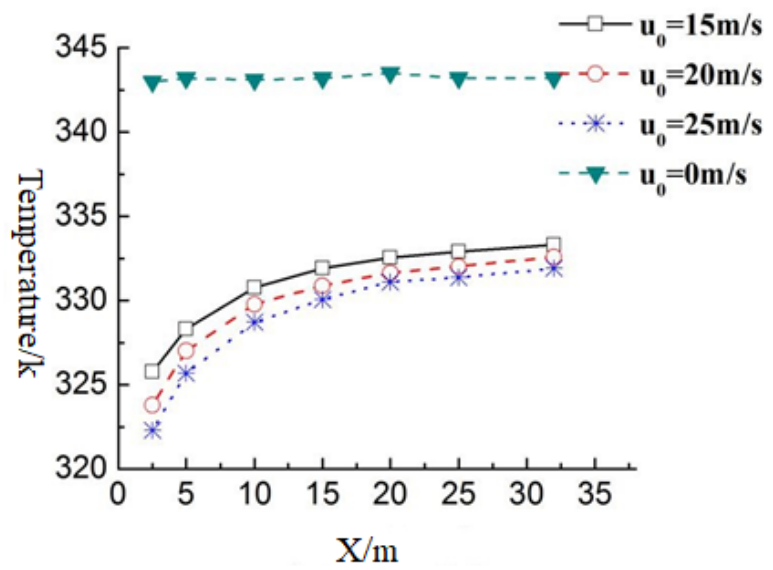

Figure 9. The outside roof surface temperature comparison under the different air supply velocity. 


\section{Conclusions}

With the research object of the roof air film formation mechanism and cooling law of large-span air-conditioning plant rooms, the author designed the roof air film cooling system based on Coanda airfoil air induction unit, constructed mathematical model and numerical simulation method of fluid-structure interaction between air film of outside surface and garret, as well as influences of solar radiation on outside surface air film on the roof, conducted the validation of effectiveness for numerical simulation method and discussed the air film formation mechanism and air film cooling ability on outside roof surface in large-span air-conditioning plant rooms without natural wind. The main conclusions were shown as follows:

1) Air film has the good formation on the roof. With the increase of air flow distance, air film area is gradually increasing and air film adherence velocity is reduced. Moreover, with the increase of air supply velocity, the air film area is more obvious.

2) Air temperature is increasing with the increase of air flow distance. There is the maximum temperature rise in the end of the roof. Moreover, with the increase of air supply velocity, the temperature rising is reducing. As closing to the outside roof surface, the air temperature is higher. Air film constantly takes away outside roof surface heat with the increase of air flow distance.

3) The outside roof surface is increased with the increase of air flow distance. with the increase of air supply velocity, the outside roof surface has the lower temperature, cooling temperature difference is larger and cooling effect will be better.

\section{Conflicts of Interest}

The authors declare no conflicts of interest regarding the publication of this paper.

\section{References}

[1] Johanna, P.K. (2014) The Impact of Cool Roofs in Different Climatic Regions: A Quantitative Empirical Analysis. University of Maryland, College Park.

[2] Kiran, V.P. (2013) Impact of Sustainable Cool Roof Technology on Building Energy Consumption. Portland State University.

[3] Mahmoud, A.S., Asif, M., Hassanain, M.A., et al. (2017) Energy and Economic Evaluation of Green Roofs for Residential Buildings in Hot-Humid Climates. Buildings, 7, 14. https://doi.org/10.3390/buildings7020030

[4] Berto, R., Stival, C.A. and Rosato, P. (2018) Enhancing the Environmental Performance of Industrial Settlements: An Economic Evaluation of Extensive Green Roof Competitiveness. Building and Environment, 127, 58-68.

https://doi.org/10.1016/j.buildenv.2017.10.032

[5] Wu, W.P., Li, C., Wu, H.D., et al. (2016) Cooling by Interior Spraying Ventilation and Roofing Sprinkling Ventilation on Open Beef Cattle Barn Improving Production Performance of Beef Cattle. Transactions of the Chinese Society of Agricultural 
Engineering, 32, 187-193.

[6] Kuroyanagi, T., Iyonaga, M. and Sunada, K. (2011) Development of CFD Model of a Greenhouse with Water-Sprinkling Roof. Acta Horticulturae, 893, 613-620. https://doi.org/10.17660/ActaHortic.2011.893.64

[7] Hunley, B.K., Nix, A.C. and Heidmann, J.D. (2010) A Preliminary Numerical Study on the Effect of High Freestream Turbulence on Anti-Vortex Film Cooling Design at High Blowing Ratio. ASME Paper No. GT2010-22077. https://doi.org/10.1115/GT2010-22077

[8] Li, J. (2011) Experimental and Theoretical Research on Gas Turbine Film Cooling. Tsinghua University, Beijing.

[9] Ding, Y., Chang, H.-P. and Du, Z.-N. (2014) Cooling Characteristics of Full Coverage Film Holes with Opposite Lateral Ejection Angels. Journal of Aerospace Power, 29, 511-518.

[10] Zhang, Y., Qi, S.-B. and Yuan, X. (2011) Experimental Investigation on the Turbine Blade Platform Film Cooling Effected by the Flow Field. Journal of Engineering Thermophysics, 32, 941-944.

[11] AbdulNour, R.S., Willenborg, K., McGrath, J.J., et al. (2000) Measurements of the Convection Heat Transfer Coefficient for a Planar Wall Jet: Uniform Temperature and Uniform Heat Flux Boundary Conditions. Experimental Thermal and Fluid Science, 22, 123-131. https://doi.org/10.1016/S0894-1777(00)00018-2 